International Journal of Engineering \& Technology, $7(2.8)(2018) 239-242$
International Journal of Engineering \& Technology
SPC
Website: www.sciencepubco.com/index.php/IJET
Research Paper

\title{
Measurement and detection of voltage dips and swells in power circuits
}

\author{
N. Shanmugasundaram ${ }^{1 *}$, R. Vajubunnisa Begum², E.N. Ganesh ${ }^{3}$ \\ ${ }^{I}$ Associate Professor/ EEE, Vels Institute of Science Technology and Advanced Studies, Pallavaram, Chennai \\ ${ }^{2}$ Associate Professor, Department of Electronics and Communication Science, JBAS College for Women, Chennai, India \\ ${ }^{3}$ Assistant Professor/EEE, Vels Institute of Science Technology and Advanced Studies, Pallavaram, Chennai
}

\begin{abstract}
The different power quality phenomena may have characteristics quite different from each other in terms of amplitude, duration, repetition, effects on the system elements, perception of users, etc. Events like interruptions and voltage dips and swells are characterized as phenomena where the root mean square (rms) value of the supply voltage falls below or rises above a prefixed threshold. Description of three-phase measurement device for detecting voltage dips and swells in electric power network is given in this paper. The device has been tested on a real electric power network and practical results of measurement are given.
\end{abstract}

Keywords: Power Quality / Voltage dips / Voltage swells / Three-Phase Measurement

\section{Introduction}

Recently, interest in the quality of electrical energy has increased greatly, for many different reasons. Modern sophisticated electronic and telecommunication equipment has become less tolerant to various disturbances in electrical power supply. The increased demand of energy utilization of sophisticated sensitive ICT and semiconductor devices at homes and offices has also led to monitoring and controlling of voltage, current profile to focus on power quality related issues like voltage dips and swells. Very complex industrial processes controlled by microprocessors and PLC devices have become very sensitive to any voltage disturbances. Because of the enormous costs of stopping complex industrial processes, large companies are intolerant of any disturbance and in such cases usually require compensation from electro distribution for damage caused. At the same time, all of today's power electronics is based on some kind of non-linear switching circuits. There are two reasons why this is so. The first one is because the linear electronic and control circuits have large temperature dissipations and losses. The second one is because of tendency to avoid the use of expensive, cumbersome and impractical transformers. Modern electronic converters and inverters are very cheap, but they generate harmonic distortion over a wide range. Deregulation on the electrical energy market has further intensified the problem because everyone wants very cheap and reliable electrical energy without the need for the implementation of high-quality and expensive electronic devices. With the emergence of new renewable energy sources also appeared completely new phenomena that previously did not exist, or very rarely occurred. Wind generators and solar power plants operate with a variable power and strong wind gusts cause abrupt voltage dips and swells without any warning. The increasing use of energy efficient light bulbs also leads to the increase of voltage disturbances. No matter that their individual power consumption is relatively small, in large number they become a significant problem. Also, the false activation of the protective relay due to a disruption in the network can leave a large number of consumers without power.

In homes and offices sudden transient on the power network can lead to restarting PC computers and damaging the hard disks. For these reasons, users as well as suppliers of electrical energy became more interested in the power quality. The term Power Quality refers exactly to this aspect of electrical energy. In the most general form, the standard IEEE 1100 (Institute of Electrical and Electronics Engineers) defines Power Quality as the concept of powering and grounding electronic equipment in a manner that is suitable to the operation of that equipment. Voltage disturbances are the most common power quality problem causing effects ranging from minor failure of equipment to the shutdown of complete production processes. Measurement of dips and swells values as well as their duration gives very important information about the state of the electric power network [1].A new technique developed for voltage dips detection in electric networks with generation and transmission system using a forward Artificial Neural Network (ANN) algorithm with sigmoid hidden neuron. Voltage dip is produced through simulation results are carried out in DIgSILENT Power Factory 14.0 software and the results are tested on IEEE 9-bus system [6]. The voltage dips and swells caused by the islanding of distributed generation (DG) are characterized by its pre- and post-islanding actions. Pre-islanding actions involves the fault originated islanding scenarios, whereas post-islanding actions are related with intermediate state, island equilibrium and grid-reconnection situations. Islanding and its subsequent actions are simulated using a test distribution network of Australia embedded with distributed generation, and the voltage dips and swells are characterized using the developed algorithm [7]. Due to the relatively poorly constructed electric power infrastructure in certain areas such phenomena become dominant. Less dangerous phenomena are network flickers, which cannot jeopardize power network as much as they are unpleasant to the human eye. 


\section{Voltage Dips and Swells}

Voltage dips represent one of the most important factors in the quality of electrical energy and the analysis of the results requires definition and understanding of the voltage drop characteristics. Different types of disturbances are classified by the amplitude and duration. This is especially important for manufacturers and users of electrical devices. Producers need to know what their equipment should withstand, and users can determine by monitoring whether the device malfunction is caused by disturbances in the network or a problem is with the device itself. The principal standards in this field are IEC 61000, EN 50160 and IEEE 1159.

Standards define types, duration of disturbance and tolerances for different types of equipment in relation to the conditions that may be present in the network. In practice, the specific voltage dips can be quite complicated and cannot be described using classical characteristics. First, despite the decrease in the amplitude when voltage drop occurs, there is a phase shift, which is not usually included in the characteristic. Second, this characteristic considers balanced voltage dip, while most of the voltage decays are caused by unbalanced failures.

When it comes to three-phase system, there are two approaches The first approach, in accordance with IEC 61000-4-30 standard takes the minimum value of the measured voltage at some phase during the voltage drop for a voltage dip value. The second approach, based on the IEEE 1564, measures voltage characteristics basing on symmetrical components and takes the minimum measured value of the six effective values, three phase and three interphase voltages. In this paper, the first approach is used.

To make the study of power quality problems useful, the various types of disturbances need to be classified by magnitude and duration. Voltage unbalance can be caused by the presence of single-phase generators, unbalanced impedance of the distribution system, and unequal loading of the phases. Fig. 1 shows the shapes of voltage dip and swell with defined parameters.
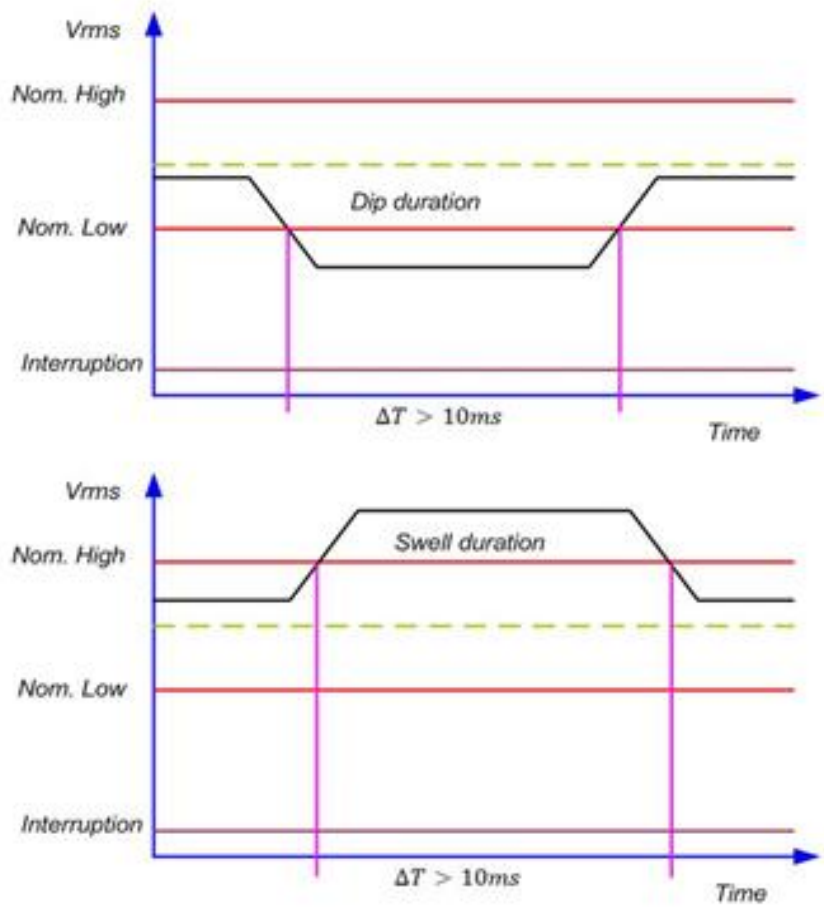

Fig. 1: The shapes of voltage dip and swell

\section{A. Voltage Dips}

The voltage dips are defined as abrupt voltage drops for more than $10 \%$ of the nominal value with duration between 10 milliseconds and a minute. The main causes of voltage drop in the power network are system failures that are far enough away, so they cannot cause a complete power shutoff, startup of large power consumers and occasional supplying of large inductive consumers. Voltage dips occur due to poorly dimensioned installations on the user side and they represent the most common cause of industrial facilities downtime. Other causes of decay in the power network are associated with weather conditions and excavations during which cables are damaged. According to standard EN 50160 [2], in which the device is made, nominal phase voltage is $230 \mathrm{~V}$ with a tolerance of $+/-10 \%$, which gives the allowable voltage range from $207 \mathrm{~V}$ to $253 \mathrm{~V}$. The lower and higher voltage values are considered as voltage dips and swells, respectively. Values measured in the interphase voltages better represent the effect of voltage drops for industrial consumers. The annual number of voltage drops is unpredictable and significantly varies from place to place.

\section{B. Voltage Swells}

Voltage swells are opposite to dips and represent the increase in voltage that can be instantaneous or have a longer duration. Instantaneous swells are defined as sudden increases in effective voltage value above $110 \%$ of the nominal voltage, with duration between 10 milliseconds and a minute. They are usually caused during the switching off inductive consumers. These effects can cause serious damages, ranging from the insulation damage to damage of sensitive electronic equipment. Instantaneous swells appear when the effective voltage value in one phase, measured during one signal period, exceeds the threshold of $110 \%$ of the nominal voltage. Measurement continues until the value in all three phases falls back below this threshold. Although the effects of a voltage dip are more noticeable, the effects of a voltage swell are often more destructive. It may cause breakdown of components on the power supplies of the equipment, though the effect may be a gradual, accumulative effect. It can cause control problems and hardware failure in the equipment, due to overheating that could eventually result to shutdown. Also, electronics and other sensitive equipment are prone to damage due to voltage swell.

\section{Flickers}

Flickering, the annoying phenomenon of light intensity changes is caused by voltage fluctuations due to changes in network load. It is very unpleasant to the human eye and is characterized by slow changes in voltage amplitude with frequencies ranging from 0.5 to $30 \mathrm{~Hz}$. Mathematically it can be easily described as an amplitude modulated waveform. The most common sources of flicker are electrical arc furnaces, motors in pumps for heating and air conditioning, kitchen appliances, copying machines and more recently alternative energy sources, such as wind generators. One standard defines regulations in this field and this is IEC 61000-4$15[3]$.

\section{Technical Characteristics of Device}

Since these excessive situations, the so-called voltage "dips", typically occur in very short time intervals, classically designed devices with some of the "true rms" integrated circuits are not considered due to their large time constants. Therefore, a microprocessor measuring device that calculates the effective value of the three-phase voltage using the classical method of sampling (1), where all changes in the form and voltage values can be easily and quickly detected, is implemented [4]. 


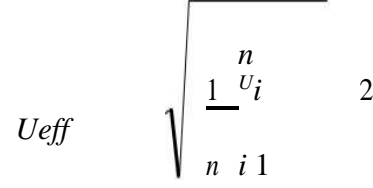

It is necessary to construct a measuring device which could withstand a minimum temperature values in this region and continue working within the specified limits of accuracy (industrial components with increased temperature working range, from $-20 \mathrm{C}$ to $+70 \mathrm{C}$ degrees, are used), with excellent robustness and reliability.

Because there was no a quality power supply at some locations, it was necessary to enable the device to work properly in a wide range of power supply. Power supply of device is carried out over three phases ( 3 times single-phase) in the range from 120 to 300 Veff. The device works and measures properly even if there is only one phase of 120 Veff. The measurement range of this device is from 0 to 300 Veff and its class of accuracy is 0.5 .

The main part of this measuring system is the microprocessor. The new generation of microprocessor $\mathrm{ADuC} 832$ produced by "Analog Devices" is selected because it contains highly accurate 12-bit AD converter with 8 analog inputs [5]. Additionally, this microprocessor also contains all the necessary components for making precision measuring devices for embedded applications. Some of them are:

- 62 Kbytes of program flash memory,

- In System Programmable chip,

- 12 bit AD converter with 8 inputs, 250 kSPS,

- 8051 industry standard,

- $\quad$ SPI, I2C, UART and DMA hardware channels,

- Timer Interval Counter and WDT Timer,

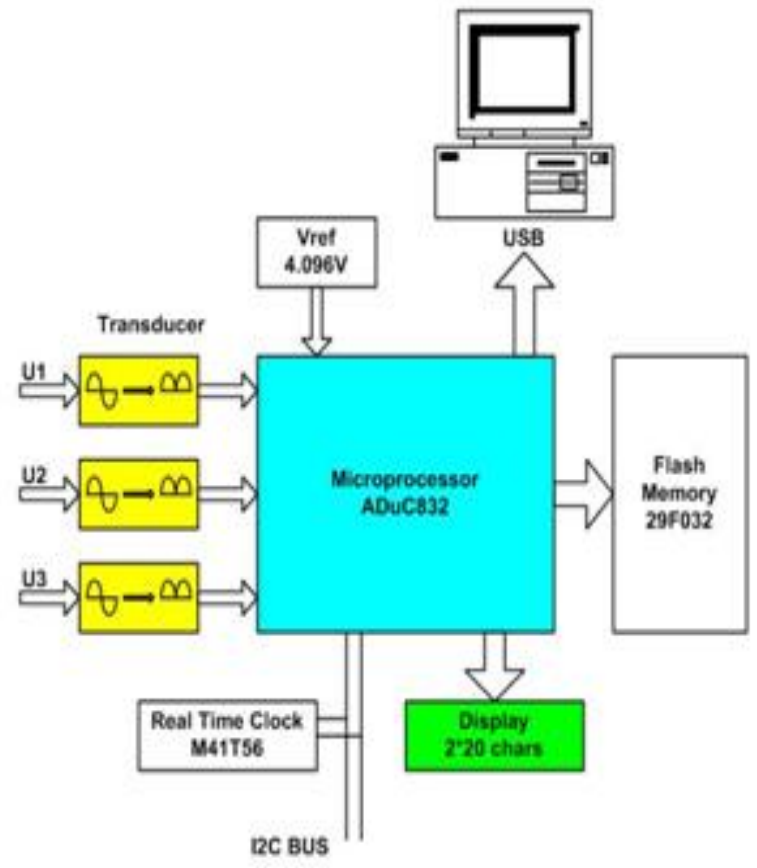

Fig. 2: Block diagram of the device

All data obtained by measurements are stored in permanent flash memory of 512 Kbytes capacity, which is sufficient for 30 days of continuous recording. The device also contains a real time clock and display. A block diagram of the device is shown in Fig. 2.

Realized device was housed in a plastic box that meets all the standards for this type of measuring devices. The appearance of the realized device is given in Fig. 3 .

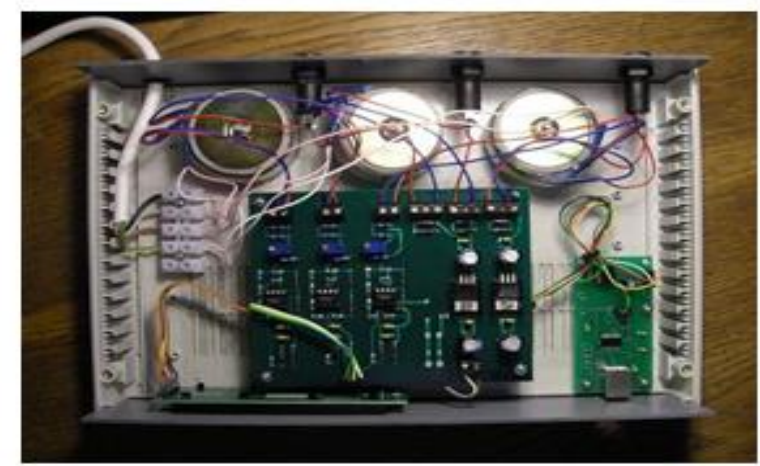

Fig. 3: Realized measurement device

Data transfer to PC is done via the USB port using Visual Basic program under the Windows operating system. The received data are automatically stored in an Excel file. Data transfer can be performed while the device is connected to the measured voltage because the device is completely electrically isolated from the measured voltage through the voltage measuring transformers. The appearance of the whole measurement system is shown in Fig. 4.

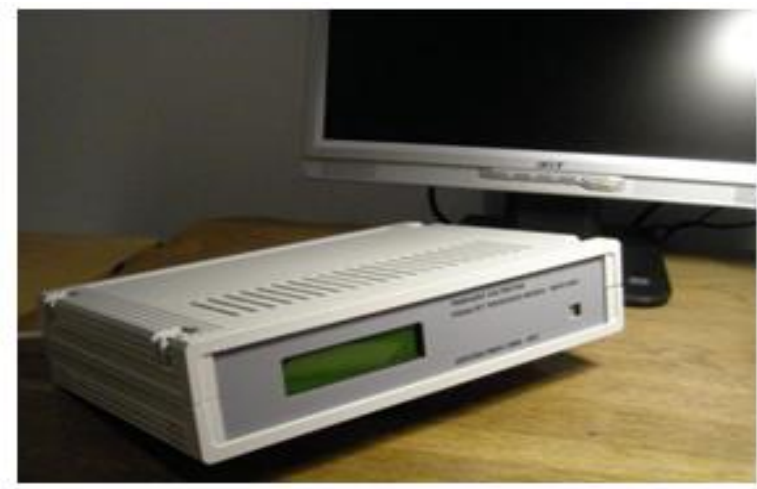

Fig. 4: Measurement system

The produced device represents the very useful measurement tool, which enables quality analysis of events in power network. Measuring device is robust and has satisfactory precision.

\section{Results and Discussion}

It is possible to put the device in the electrical power station or other power facility to perform continuous measurements. By now, it is used as a portable device, which is installed on the user's demand at his place, to collect data from the power network. The layout of the numeric data in Excel software package, which is automatically formatted by Visual Basic program, is shown in Fig. 5.

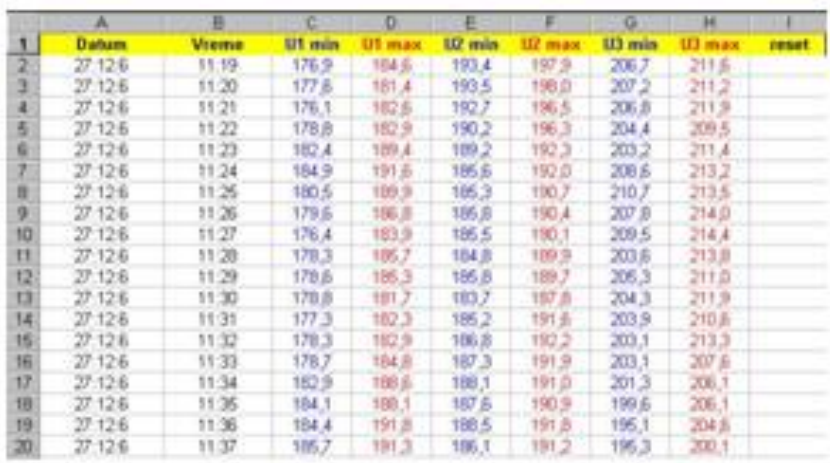

Fig. 5: Measurement results in Excel program 
Graphically presented results of measurements are shown in Fig.6. From graphics it can be seen that there is a big difference in voltage by phases, probably due to asymmetry of the phase load. In one phase the voltage value falls below the minimum requirement. This voltage value is maintained throughout the day and during the night raises to a satisfactory level. It can be noted that there is a big difference in the phase voltage between day and night. The voltage is higher at night for about $40 \mathrm{~V}$.

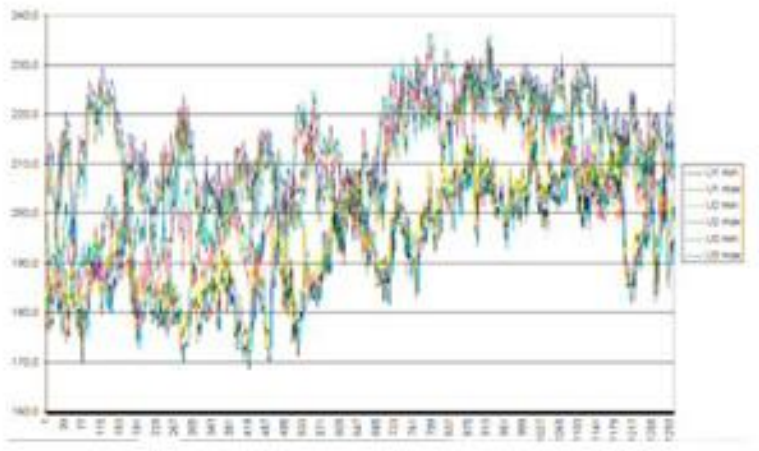

Fig. 6: Graphical display of measurement data

However, from a more detailed graphic it can be claimed that there are no sudden dips, swells and flickers in the power network. This is shown in Fig. 7.

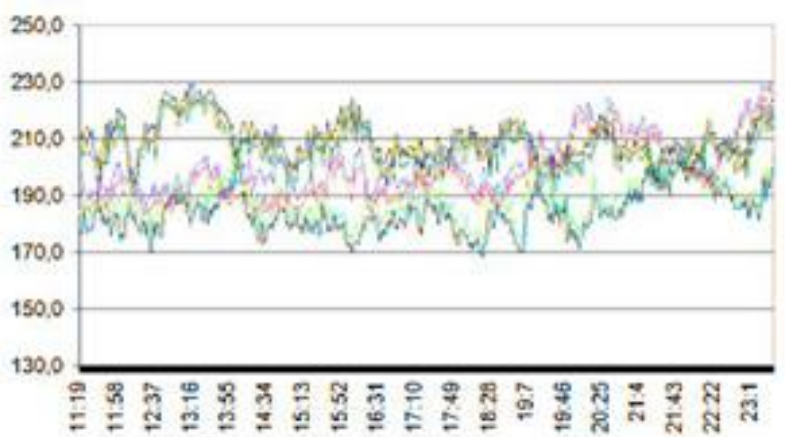

Fig. 7: Detailed overview of measurement data

On the new graphic are given measurement results for which it is observed that in addition to voltage fluctuations in the regime of the day-night there are also indications of a sudden voltage drops which can be read in all three phases simultaneously. They probably originate from the inclusion of a larger three-phase consumer. It is also evident that there is not a big difference in the values of phase voltages and voltages are kept within acceptable limits. This is shown in Fig. 8.

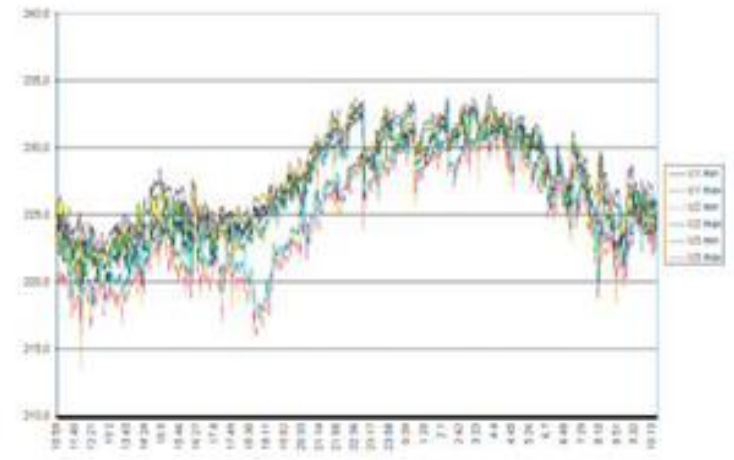

\section{Conclusion}

In the new market conditions, there were large changes in the production and distribution of electrical energy. Now, the electrical energy is goods like any other with which it is traded on the free market, but which also has to meet certain criteria in terms of quality. Widespread application of power electronics, especially in distribution networks, has led to various problems related to the proper operation of the system, caused by distortion of voltage and current. The produced device represents the very significant tool for engineers working in power distribution companies. This device enables quality analysis of events in power network in order to raise the quality of electricity. From the results obtained from the field measurements it is concluded that this instrument is very robust and has satisfactory precision. Measurement data are easily transferred to a computer for further processing.

\section{References}

[1] Math H. J. Bollen, "Understanding power quality problems: voltage sags and interruptions", IEEE Press, 2000.

[2] H. Markiewicz, A. Klajn, "Voltage Disturbances Standard EN 50160", Wroclaw University of Technology, 2004.

[3] IEC 61000-4-15, Electromagnetic compatibility - Testing and measurement techniques-Flickermeter-Functional and design specifications, IEEE Power \& Energy Society, 2010.

[4] Carlo Muscas, "Power Quality Monitoring in Modern Electric Distribution Systems", IEEE Instrumentation \& Measurement Magazine, 2010.

[5] ADuC832 Data Sheet, Analog Devices Inc., 2009.

[6] O.Ipinnimo, S.Chowdhury, S.P.Chowdhury and J.Mitra"Intelligent voltage dip detection in power networks with distributed generation (DG)"North American Power Symposium (NAPS), Pages: $1-6$, Year: 2012

[7] M. R. Alam, K. M. Muttaqi, A. Bouzerdoum "Characterization of voltage dips and swells in a DG embedded distribution network during and subsequent to islanding process and grid reconnection" IEEE Industry Applications Society Annual Meeting, Pages: 1 - 9, Year: 2017.

[8] Mahesh Mudavath, K Hari Kishore, D Venkat Reddy "Design of CMOS RF Front-End of Low Noise Amplifier for LTE System Applications Integrating FPGAs" Asian Journal of Information Technology, ISSN No: 1682-3915, Vol No.15, Issue No.20, page: 4040-4047, December 2016

[9] T. Padmapriya and V.Saminadan, "Handoff Decision for Multiuser Multiclass Traffic in MIMO-LTE-A Networks", 2nd International Conference on Intelligent Computing, Communication \& Convergence (ICCC-2016) - Elsevier PROCEDIA OF COMPUTER SCIENCE, vol. 92, pp: 410-417, August 2016.

[10] S.V.Manikanthan and K.Baskaran "Low Cost VLSI Design Implementation of Sorting Network for ACSFD in Wireless Sensor Network", CiiT International Journal of Programmable Device Circuits and Systems,Print: ISSN 0974 - 973X \& Online: ISSN 0974 - 9624, Issue : November 2011, PDCS112011008.

[11] S.V.Manikanthan and K.srividhya "An Android based secure access control using ARM and cloud computing", Published in: Electronics and Communication Systems (ICECS), 2015 2nd International Conference on 26-27 Feb. 2015,Publisher: IEEE,DOI: 10.1109/ECS.2015.7124833.

[12] K. Ramash Kumar, Dr.S. Jeevananthan,” Design of a Hybrid Posicast Control for a DC-DC Boost Converter Operated in Continuous Conduction Mode" (IEEE-conference PROCEEDINGS OF ICETECT 2011), pp-240-248, 978-1-4244$7925-2 / 11$.

Fig. 8: Graphical display of measurement data 